\title{
El tema de los amantes que mueren abrazados y/o besándose: de Johannes Secundus y Lope de Vega a Lorca y Neruda
}

\section{The Theme of Lovers Dying Holded and/or Kissing: from Johannes Secundus and Lope de Vega to Lorca and Neruda}

\author{
Bienvenido Morros Mestres \\ Universidad Autónoma de Barcelona \\ bienvenido.morros@uab.es \\ ORCID iD: https://orcid.org/0000-0002-4285-1079
}

\begin{abstract}
RESUMEN
El poeta holandés Johannes Secundus Everaerts incluyó un poema en sus Basia (1541) que fue imitado por poetas españoles y franceses de diferentes épocas. El poema de Secundus tiene la peculiaridad de presentar a los amantes abrazándose y/o besándose en el momento de la muerte para llegar juntos al más allá convertidos en un solo ser (y los amantes toman como ejemplo de su unión tanto física como espiritual el de la yedra adherida al tronco de cualquier árbol). Lope de Vega fue el autor que lo imitó más literalmente, pero no el único que ejerció su influencia en los poetas posteriores: Pierre Ronsard y Juan Meléndez Valdés, quienes se basaron en otro poema de los Basia, se convirtieron en modelos fundamentales de Federico García Lorca y Pablo Neruda. El poeta granadino se inspiró también en la muerte de Adonis tanto en la versión de Bión como la de Ovidio.
\end{abstract}

Palabras Clave: Historia literaria; poesía europea e hispanoamericana; amor y muerte; mitología.

\begin{abstract}
The Dutch poet Johannes Secundus Everaerts included a poem in his Basia (1541) that was imitated by Spanish and French poets of different times. The poem of Secundus has the peculiarity of presenting lovers embracing and / or kissing at the moment of death to arrive together to the hereafter converted into a single being (and lovers take as an example of their union both physical and spiritual the The yedra attached to the trunk of any tree). Lope de Vega was the author who imitated him more literally, but not the only one who exerted his influence on the later poets: Pierre Ronsard and Juan Meléndez Valdes, who were based on another poem of the Basia, became fundamental models of Federico García Lorca and Pablo Neruda. The great poet was also inspired by the death of Adonis in both the version of Bion and that of Ovid.
\end{abstract}

Key words: Literary history; European and Hispanic American poetry; Love and death, Mythology. 
En la parte final de La Circe (Madrid, 1624) Lope de Vega recoge unos cuantos sonetos que traducen o recrean epigramas neolatinos, cuyo texto íntegro introduce al frente de cada uno de ellos en su lengua original y también en cursiva. Es el caso, por ejemplo, del soneto «Subió, atrevido, miserable enano», traducción bastante literal del epigrama de Johannes Secundus (o Jan Everaerts), «Ausus formica nanus condescendere tergum» (Vega 1983, 1298-199). Los dos poetas describen la ridícula acción de un enano que sube a las espaldas de una hormiga y que, después de perder el equilibrio, cae al suelo teniendo la sensación de haber caído desde el cielo como un nuevo Faetón. Lope añade una moraleja dirigida a un ficticio enemigo Lidio para tranquilizarle sobre el daño que pueda ocasionarle porque se considera con el poder de una hormiga y no con el de Júpiter, quien fulminó al hijo del sol y lo hizo caer desde la bóveda celeste. Bastantes años antes, como veremos a continuación, había compuesto un soneto, incluido en sus Rimas (Madrid, 1602), en el que recrea desde el primer al último verso uno de las poemas del libro más famoso del holandés, los Basia, editados en 1541 y muy imitados en el Renacimiento y Barroco europeos, pero también en el siglo XX especialmente a través de la versión que hicieron los poetas franceses. En este último soneto Lope no ofrece ninguna referencia sobre su fuente, pero su conocimiento ayuda a entenderlo mucho mejor y a descartar algunas de las interpretaciones peregrinas que se han dado de los cuartetos ${ }^{1}$. Lope divide su soneto en dos partes muy diferenciadas: en una primera enumera las cosas que no le causan ninguna preocupación y en la segunda se dirige a Lucinda para pedirle afrontar la muerte abrazados como lo están la yedra y el olmo (piensa que ese es el único modo que su deseo pueda sobrevivir a las aguas del río Leteo). Esas dos partes están mezcladas en el poema de Johannes Secundus, y de igual modo han de entenderse en nuestro soneto, como intentaremos demostrar en las siguientes páginas:

Yo no espero la flota, ni importuno al cielo, al mar, al viento por su ayuda, ni que segura pase la Bermuda sobre el azul tridente de Neptuno;

ni tengo hierba en campo, o rompo alguno

con el arado en que el villano suda,

ni del vasallo que con renta acuda

provecho espero en mi favor ninguno.

Mira estas hiedras, que con tiernos lazos, para formar sin alma su himineo dan a estos verdes álamos abrazos.

${ }^{1}$ Algunos críticos han atribuido las preocupaciones que Lope de Vega deja de tener al pensar en el abrazo de Lucinda a preocupaciones reales suyas, como las idas y venidas del marido de Micaela Luján a Sevilla de las Indias; tampoco es necesario suponer al autor en un lugar en concreto para justificar que esté o no pendiente de la llegada de la flota (para todas estas cuestiones véase Pedraza 1993, 369). 


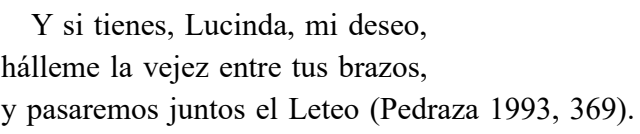

En los cuartetos el poeta elige a tres grupos sociales como referentes que a él no parecen afectarle en nada: los marineros y/o comerciantes, los agricultores y los grandes señores dedicados a cobrar impuestos (ibíd., 368). En los tercetos, en cambio, da un giro inesperado hacia el tema amoroso al proponerle a Lucinda la muerte entre sus brazos para atravesar juntos las aguas del río Leteo y seguir amándose no más allá de la muerte sino también del olvido: aparte en el poeta holandés también se había inspirado en la simbología de la vid y el olmo sintetizada por Alciato con la inscripción «La amistad que dura aún después de la muerte», como dejó claro Aurora Egido en su magistral trabajo (1982, 213-214, n. 2, y 225). Es llamativa, creo, la falta de conexión entre los cuartetos y los tercetos, pero solo es aparente esa falta de conexión, como veremos al leer el poema que ha inspirado nuestro soneto. Johannes Secundus empieza centrando la atención en las plantas que simbolizan el tipo de unión que reclama a su amada Neera para emprender de ese modo el viaje hacia el más allá en la misma barca. Imagina que en el momento en que consiga esa unión tan deseada no habrá ya nada que distraiga su atención ni que le inquiete lo más mínimo: al igual que Lope menciona tres preocupaciones, las de Ceres, propias de los agricultores, las de Lieo, apodo de Baco, concernientes sobre todo a los viñateros, y las del Sueño, relacionadas con emperadores y reyes, quienes lo invocaban para poder conciliarlo². Nuestro dramatur-

2 Johannes Secundus pudo inspirarse en el mito de Baco y Ciso para elaborar el motivo de la yedra y el olmo como símbolo del amor eterno. Ciso era bailarín y amante de Baco, y bailando cayó mortalmente en un zanja, pero de su interior creció la planta a la que dio nombre, la yedra, para ya abrazarse eternamente a su amante, la vid (Rodríguez Alfageme 2006). El poeta holandés pudo también tener en cuenta el epigrama en que Michele Marullo ofrece la versión del suicidio de Laodamia tras recibir la visita desde el más allá de su difunto marido, Protesilao; al cumplirse el plazo de tres horas fijado por los dioses, la sombra del cónyuge debe regresar al mundo de donde ha llegado, dejando a su esposa sin sus besos y abrazos (y es por ese motivo por el que ella decide seguirlo, para gozar al menos de esos grados del amor): «Dum fugit amplexus evanida coniugis umbra/ osculaque ab Stygiis usque petita vadis,/ 'Quo sine me' inquit, 'amans? Non est ratis ima puellis/ Clausa: satis, satis, o, sola relicta semel!'/ Dixit, et in mediis subito collapsa querelis,/ Magnanimo comes it Laodamia viro» (Epigrammaton, III, 8). En Le Parnasse des poètes satiriques, se incluyó un soneto anónimo, pero seguramente de Théophile de Viau, inspirado en este epigrama (y en el mito de Protesilao y Laodamia): «Je songeais que Philis des enfers revenue,/ Belle comme elle était à la clarté du jour,/ voulait que son fantôme encore fit l'amour/ el que comme Ixion j'embrassasse une nue./ Son ombre dans mon lit se glissa toute nue/ et me dir: 'Cher Tircis, me voici de retour,/ je n'ai fait que'embellir en ce triste séjour/ où depuis ton départ le sort m'a retenue./ Je viens pour rebaiser le plus beau des amants,/ je viens pour remourir dans les embrassements'./ Alors, quand cette idole eut abusé ma flamme,/ elle me dit: 'Adieu, 
go recrea con bastante literalidad los catorce primeros versos y apenas tiene en cuenta los otros dieciocho por haber dejado claro el lugar al que se dirigirá junto a Lucinda tras la muerte de ambos:

Vicina quantum vitis lascivit in ulmo, et tortiles per ilicem

brachia proceram stringunt immensa corymbi, tantum, Neera, si queas

in mea nexilibus proserpere colla lacertis, tali, Neera, si queam

candida perpetuum nexu tua colla ligare, iungens perenne basium,

Tunc me nec Cereris, nec amici cura Lyaei, Soporis aut amabilis,

vita, tuo de purpureo divelleret ore; sed mutuis in osculis

defectos, ratis una duos portaret amantes ad pallidam Ditis domum.

Mox per odoratos campos et perpetuum ver produceremur in loca,

semper ubi, antiquis in amoribus, Heroinae

Heroas inter nobiles

aut ducunt choreas, alternaue carmina laetae in valle cantant myrtea,

qua violisque, rosisque, et flavicomis narcissis umbraculis trementibus,

illudit lauri nemus, et crepitante susurro tepidi suaue sibilant

aeternum Zephyri; nec vomere saucia tellus fecunda soluit ubera.

Turba beatorum nobis assurgeret omnis; inque herbidis sedilibus,

inter Maeonidas prima nos sede locarent: nec ulla amatricum Iovis

praerepto cedens indignaretur honore, nec nata Tyndaris Iove (88-89).

Lope traslada al final la petición a la amada, pero la formula en los mismos términos que el poeta holandés: "Y si tienes, Lucinda, mi deseo», «Neaera, si queas/ in mea nexilibus [...]/ Neaera, si queam/ candida». Lope adelanta las referencias a las cosas que no le importan porque ya las desecha antes de saber si Lucinda aceptará su propuesta de morir enlazados, pero las introduce también, al igual que su modelo, con la partícula negativa: «Yo no espero la flota, ni importuno $[\ldots]$ ni que segura $[\ldots]$ ni tengo hierba $[\ldots]$ ni del vasallo», «nec

je m'en vais chez les morts./ Comme tu t'es vanté d'avoir f... mon corps,/ Tu pourras te vanter d'avoir f... mon âme» $(1622,206-207)$. 
Cereris, nec amici cura Lyaei,/ Soporis aut amabilis». Johannes Secundus y Lope pretenden surcar las aguas que han de llevarles al más allá abrazados a sus respectivas amadas pensando que si lo hacen de esta manera ni la muerte ni el olvido ya los podrá desunir: «raris una duos portaret amantes/ ad palllidam Ditis domum», «y pasaremos juntos el Leteo». Lope acaba en este punto su poema mientras que Johannes Secundus lo prolonga para describir el lugar de los bienaventurados al que está convencido que llegará acompañado por Neera. Para la geografía del lugar el poeta holandés sigue fundamentalmente una de las elegías de Tibulo (I, 3, 57-66), que había mezclado las Olímpicas de Píndaro (II, 56-82) con la Eneida de Virgilio (VI, 635-665). En esa geografía del Hades, el mundo de los muertos, Lope menciona el río Leteo, uno de los ríos del Hades, situado delante de las «domos placidas» (VI, 705), las de los bienaventurados, en un lugar apartado junto también a un bosquecillo. El Leteo es el río de cuyas aguas beben las almas que desean volver al cielo para, olvidadas por completo de su vida anterior, la vinculada a los cuerpos de las que se han liberado, descender a la tierra y encarnarse en nuevos cuerpos. El mensaje de Lope es claro: si las plantas, sin un alma inmortal, están para siempre unidas, ¿cómo no habrán de estarlo dos cuerpos, convertidos en una sola alma inmortal, tras cruzar las aguas del olvido? La única posibilidad de seguir experimentando el mismo deseo que en vida radica en surcar el río Leteo, cuyas aguas consiguen extinguirlo con absoluta efectividad, tan fuertemente abrazados y unidos como lo están la yedra y el olmo .

Antes que Lope, Pierre Ronsard había recreado también en un soneto el poema de Johannes Secundus, pero el soneto en cuestión, seguramente por su contenido erótico, apareció póstumamente entre sus «Huict sonnets [...] non imprimez en ses oeuvres» (77) en Le parnasse des poetes satyriques or dernier des vers piquants ([París], 1622). Ronsard, que había elogiado al poeta holandés en su «Oda à Nicolas Deniset» (Odes, V, 11), ha tenido también en cuenta un famoso epigrama de Catulo, muy presente en otras elegías de Johannes Secundus:

\footnotetext{
Maîtresse embrasse-moi, baise-moi, serre-moi, haleine contre haleine, échauffe-moi la vie, mille et mille baisers donne-moi, je te prie; amour veut tout sans nombre, amour n'a point de loi.
}

${ }^{3}$ Johannes Secundus pudo haberse inspirado en unos versos de la primera égloga de Giovanni Pontano, titulada Lepidina (Venecia, 1505), en los que Macron recuerda los besos intensísimos que se daba con su cónyuge Lepidina. Los alientos de los esposos se confundían en uno solo, de suerte que si en ese momento el Orco los hubiera raptado para el inframundo sus almas enamoradas habrían llegado a él fundidas en una sola sombra: «Illa, uxor, memini nunc, oscula prima fuere:/ Nostra tuis, tua labra meis haesere, diuque/Spiritus alterno huc illuc se miscuit ore./ Tunc Orcos si nos una rapuisset, amantum/ Una futura anima, una etiam simul umbra futura» (vv. 18-22; Pontano 1973, 24). 
Baise et rebaise-moi, belle bouche, pourquoi te gardes-tu là-bas, quand tu seras blêmie, à baiser, de Pluton ou la femme ou l'amie, n'ayant plus ni couleur ni rien semblable à toi?

En vivant presse-moi des tes lèvres de rose, bégaye, en me baisant, 'a lèvres demi-closes mille mots tronçonnés, mourant entre mes bras.

Je mourrai dans les tiens, puis, toi ressuscitée je ressusciterai. Allons ainsi là-bas.

Le jour tant soi-il court vaut mieux que la nuitée (Le parnasse, 77).

Ronsard otorga a la petición que hace a su amada la fórmula del «collige, virgo, rosas» ausoniano, al igual que Catulo en su poema «Vivamus, mea Lesbia, atque amemus» en que invita a su amada a darle un número incontable de besos antes de dormir la noche eterna. Lope, por su parte, no tiene ninguna urgencia porque solo pretende que la muerte, cuando haya envejecido al lado de Lucinda, los sorprenda en una actitud amorosa, como en la elegía de Johannes Secundus y en el soneto de Ronsard. Es posible que el poeta parisino describa dos muertes, una producida por la unión sexual con su amada y otra real tras sufrir la del primer tipo: como la vida es tan breve no debe perderse el tiempo y resulta preferible que la muerte sorprenda a los amantes en pleno acto sexual. Para el sentido erótico de la muerte, el poeta francés sin duda ha tenido presente otro poema en que Johannes Secundus, agotado y destrozado por la relación sexual con Neera, sin aliento alguno, cree estar ya cruzando la laguna Estigia en la barca de Caronte cuando por el poder de un beso de su amada se siente regresar del viaje que había emprendido (y así con la posibilidad de iniciar, ya en una sola alma, merced a un beso, otro definitivo con ella):

Languidus e dulci certamine, Vita, iacebam exanimis, fusa per tua colla manu.

Omnis in arenti consumptus spiritus ore, flamine non poterat cor recreare novo.

Iam Styx ante oculos, et regna carentia sole, Luridaque annosi cymba Charontis erat, cum tu suaviolum educens pulmonis ab imo, afflasti siccis irrigum labiis,

suaviolum, Stygia quod me de valle reduxit, et iussit vacua currere nave senem $][. .$.

Ac nisi dilecta per te foueatur ab aura, iam collabentes deserit articulos.

Ergo, age, labra meis innecte tenacia labris, assidueque duos spiritus unus alat,

donce, inexpleti post taedia sera furoris, unica de gemino corpore vita fluet (XIII, 1-10).

En unas «stances» intercaladas entre los sonetos de Les Amours de Casandre, publicados en París en 1552 en un volumen con el título genérico de Les 
amours junto a los Amours de Marie, los Sonnets et madrigals per Astrée y los Sonnets pour Héléne, Ronsard hace a su amada un planteamiento muy similar al recordarle, en los mismos términos formulados por Asclepiades en uno de sus epigramas recogidos en la Antología griega $(\mathrm{V}, 85)$, que en el Hades habrá perdido los encantos que tiene en vida (e introduce la misma referencia a Plutón y sus amigos como una alternativa en el más allá) ${ }^{4}$.

Mais quand au lit nous serons

entrelacés, nous ferons

les lascifs selon les guises

des amants qui librement

pratiquent folâtremente

dans les draps cent mignardises.

Pourquoi donque, quand je veux

on mordre tes beaux cheveux,

ou baiser ta bouche aimée,

ou toucher à ton beau sein,

contrefais-tu la nonnain

dedans un cloître enfermée?

Pour qui grades-tu tes yeux

et ton sein délicieux,

ton front, ta lèvre jumelle?

En veux-tu baiser Pluton

là-bas, après que Charon

t'aura mise en sa nacelle?

Après ton dernir trépas,

grêle, tu n'auras là-bas

qu'une bouchette blêmie;

et quand mort je te verrais

aux Ombres je n'avouverais

que jadis tu fus m'amie.

Ton test n'aura plus de peau, ni ton visage si beau

n'aura veines ni artères:

tu n'auras plus que les dents

telles que'on les voit dedans

les têtes de cimèteres.

Donque tandis que tu vis, change, Maîtresse, d'avis, et en m'épargne ta bouche.

${ }^{4}$ El epigrama de Asclepiades fue traducido por primera vez al latín en el Florilegium (Utrecht 1604) de Eilhardo Lubino: «Parcis virginitati! Quid tum postea? Non enim ad inferos/ veniens invenies amantem puella./ In viventibus voluptates Veneris; in vero Acheronte/ ossa \& cinis, virgo, iacebimus» (fol. 1009). Pierre Ronsard debió de leerla en su versión original porque la Antología griega, desde la primera edición en 1494, contó con muchas ediciones a lo largo del siglo XVI (véase López Poza 2005, 24-31). 


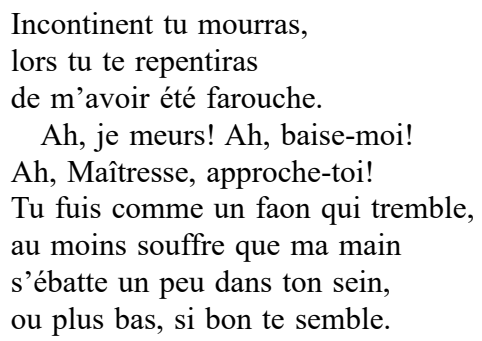

El poeta francés no exige la reciprocidad en el amor como garantía de su continuidad en el reino de la muerte sino como única posibilidad de consumarlo en vida al creer que en el más allá no va a reconocerla ni admitirla como amante. En el soneto previo a estas «stances» procede a la misma invitación a la desdeñosa Casandra en la misma convicción de Asclepiades de que el cuerpo, ya sin alma, acaba convirtiéndose en cenizas que carecen de sensibilidad (en este caso el pretexto para la reciprocidad no es la fealdad en que se convertirá la amada cuando descienda al Hades sino la inexistencia de amor en sus dominios):

Appprends à vivre, ô fiére en cruauté, en garde point à Pluton ta beauté, quelque peu d'aise en aimant il faut prendre.

Il faut tromper doucement le trépas; car aussi bien sous la terre là-bas sans rien sentir, le corps n'est plus que cendre (CXXXV, vv. 9-14).

En el soneto censurado, el primero que hemos citado por su estrecha relación con el poema de Johannes Secundus y el soneto de Lope, Ronsard no había hecho más que dar sentido trascendente al epigrama de Catulo seguramente a través de la versión que Olivier de Magny incluyó entre los sonetos (el LXVII) de Les souspirs (París, 1557):

Vivons, Belle, vivons et suivons notre amour, de cent divers plaisirs bien heurant notre vie, sans estimer en rien le babil de l'envie quid du bonheur d'autrui se tourmente toujours;

le soleil s'en va bien et revient chaque jour, mais depuis que la mort notre vie a ravie, et qu'une fois en bas notre ombre l'a suivie, il en faut plus, Maîtresse, espérer du retour.

Suivons doncques hereux notre amour fortunée, et vivons peu soigneux du jour à la journée sans songer aux jaloux, n'au trépas inhumain.

Périsse cettui-là qui d'ardente malice brasse un mal dessous nous et cil périsse aussi qui se ronge l'esprit du soin du lendemain (fol. $23 \mathrm{v}^{\circ}$ ) 
Olivier de Magny propone a su amada seguir amándose porque tras la muerte sus sombras bajarán hasta el Hades sin ninguna esperanza de retorno o regreso al mundo de los vivos. Pierre Ronsard, en cambio, trata de convencer a la amada de que la única posibilidad de amor más allá de la vida es ser sorprendidos por la muerte practicando los dos el acto sexual. Johannes Secundus también había dado a entender la misma idea y Lope no la había desechado al saber que la unión de la yedra con el olmo constituía una imagen de la unión física de los amantes. Un poeta contemporáneo y amigo de Ronsard, Rémy Belleau, había compuesto un libro a imitación del holandés con el mismo título de Baisers que repartió entre la primera y segunda parte de su Bergerie (París, 1565). El libro está compuesto mayoritariamente por sonetos pero en ninguno de ellos el poeta propone a la amada un abrazo o beso conjunto para morir llevando a cabo esos dos grados del amor como garantía de un amor eterno. En muchos de esos sonetos el amante solicita a la amada un beso para morir él solo con la mayor felicidad posible, y en uno solo añade abrazos con exhortaciones iniciales a su interlocutora muy similares al soneto de su amigo Ronsard:

Embrasse-moi, mon coeur, baise-moi, je t'en prie, presse-moi, serre-moi! À ce coup je me muers! Mais ne me laisee pas en ces douces chaleurs: car cést 'a cette fois que je te perd, ma vie.

Mon ami, je me muers et mon âme assouvie d'amour, de passions, de plaisirs, de douceurs, s'enfuit, se perd, s'écoule et va loger ailleurs, car ce baiser larron me l'a vraiment ravie.

Je pâme! Mon ami! Mon ami, je suis morte! Hé! ne me baisez plus, au moins de cette sorte. C'est ta bouche, mon coeur, qui m'avance la mort.

Ote-la donc, m'amour, ote-la, je me pâme!

Ote-la, mon ami, ote-la, ma chère âme, ou me laisse mourir en ce plaisant effort!

Philippe Desportes, de una generación ya posterior a los otros dos poetas franceses, compuso una canción titulada Baiser como parte de su obra miscelánea Bergiers (en Les ouvres, 1592) en la que imita en varios aspectos el poema de Johannes Secundus abogando incluso por la trascendencia de su amor (no la reproduzco completa sino que selecciono solo los versos directamente relacionados con su modelo):

Fay que je vive, e fay qu'à la mesme heure baissant les yeux, entre tes bras je meure, languissant doucement.

Puis qu'aussi tost doucement je reuiue, pour amortir la flamme ardante \& viue qui me va consumant. 


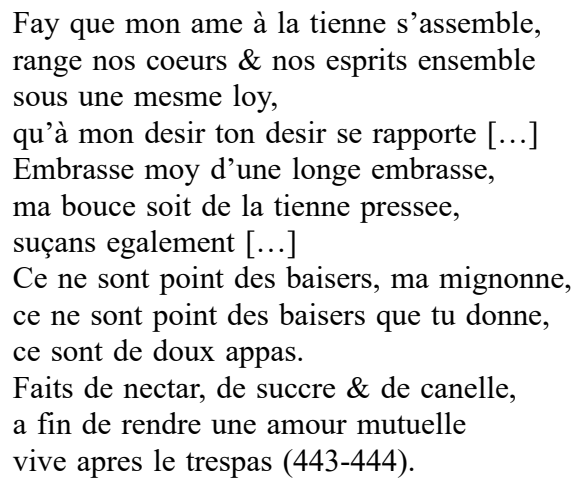

Como Lope, Desportes solicita antes a la amada compartir el mismo deseo que él para experimentar un amor recíproco capaz de perdurar después de haber cruzado el Aqueronte: la palabra «trespas» parece usarla con el sentido de «droit de passage, de transit» (Godefroy 1888, 54), en alusión al pago de un óbolo hecho a Carón por atravesar con su barca la ribera que conduce de la vida a la muerte. Es el único poeta francés que junto a Ronsard recrea muy claramente los versos 11-14 del poema de Johannes Secundus:

Sed mutuis in osculis

defectos, ratis una duos portaret amantes ad pallidam Ditis domum.

En un poema que reproduce a continuación y en el que plantea hasta qué punto la ausencia del amado puede acarrear olvido, Desportes acaba dejando claro el sentido de los versos anteriores:

La vrayre amour est tousiours vive et en meurt point par le trespas (448).

El poeta de origen portugués Gregorio Silvestre compuso un soneto, publicado entre sus Poesías (Granada, 1582), con los ingredientes del beso y la yedra unida al olmo en el que imagina a su amada doña María bebiéndose el aire de su boca "haciendo de dos almas una vida» y teniendo también su cuerpo hecho uno con el suyo como si fueran Sálmacis y Hermafrodito $(1939,248)$. Silvestre no especifica si ese beso y esa unión física y espiritual han de durar para siempre y si por consiguiente la muerte los podrá sorprender a él y a su amada estando en esa postura y con semejante actitud. La comparación con la ninfa Sálmacis y Hermafrodito, transformados en un solo cuerpo con los dos géneros después de su rela- 
ción sexual, podrían confirmar que el portugués pensaba también en una unión para siempres.

En el siglo XVIII, Juan Meléndez Valdés recreó los diecinueve poemas de los Basia, impresos entre sus Poesías (Madrid, 1985), ya a partir del original o bien a través de la versión francesa que Claude Joseph Dorat dio a conocer en Les baisers, précedes du Mois de mai, poeme (La Haye, 1770). El poeta francés interpretó correctamente el poema comentado de Johannes Secundus al titularlo «L'extase», en referencia al climax de placer alcanzado en el momento de la muerte (y también entendió las «cura [...] Soporis» como las propias de los poderosos y aristócratas, al igual que Lope de Vega):

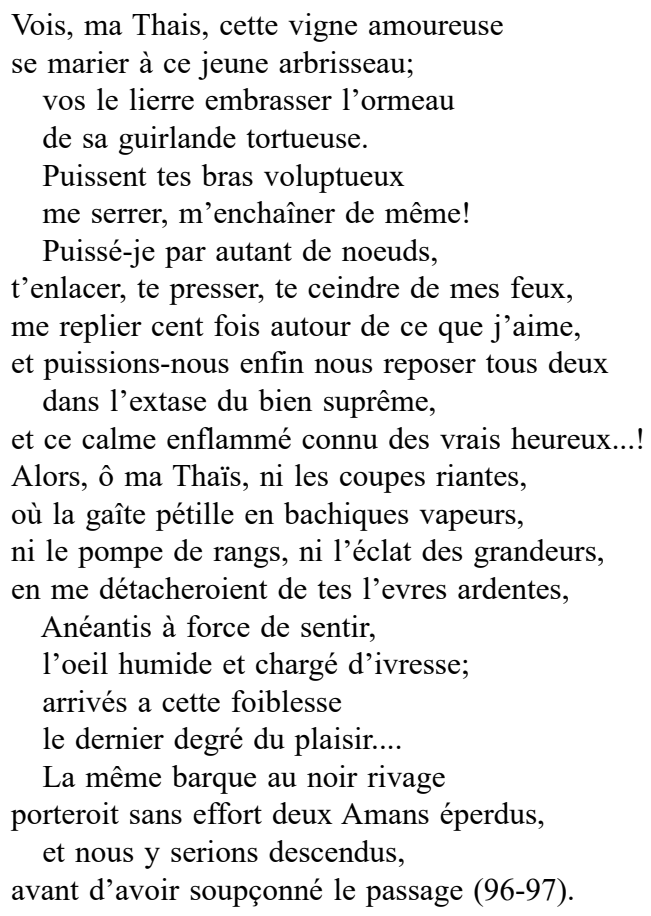

Es evidente que Meléndez Valdés conoció esta versión para la oda en la que pide la llegada de la muerte, al estilo de la famosa canción del comendador Escrivá, al alcanzar el éxtasis amoroso con Filis (y confunde el éxtasis amoroso con la muerte real) ${ }^{6}$ :

\footnotetext{
${ }_{5}$ El soneto ha sido magistralmente estudiado y comentado por Blecua, quien sitúa el soneto entre «las corrientes neoplatónicas renacentistas, que tratan con especial interés la función del beso como medio para lograr la unión de las almas» $(2006,199)$.

${ }^{6}$ La canción del comendador Escrivà fue publicada en el Cancionero General compilado por Hernando del Castillo (Valencia, 1511): «Ven, muerte, tan escondida,/ que no te
} 
De besos regalados, de amores, de caricias, en tu mullido lecho lléname, Filis mía, y enrédate a mi cuello, las bocas tan unidas, que tú mis aires bebas, yo tu aliento reciba.

Tus dos ojuelos brillen, y al entrarse lasciva con blando afán mi mano por la dorada cima, suene un murmullo blando, y a par de la fatiga dulcísima de Venus con débil voz suspira.

Tus quejidos me alienten, muérdame tu lengüita, tus brazos me aprisionen, tu anhelo me dé prisa,

y nega, ¡ay me!, la muerte, que entre tanta delicia, Filis, si llegar osa no es muerte sino vida.

En otra de sus odas Meléndez Valdés imagina que la muerte lo sorprenda no durante el acto sexual con su amada sino dándole un beso para que una misma alma salga de sus bocas en el momento de abandonar esta vida:

Di, di, ¿no sientes si me estás besando que a los labios concurren las almas y buscando la mitad que les falta, ambas discurren?

Así, mi vida, así, paloma mía, las almas ayuntemos, y tal que en ningún día tan dulcísimo lazo separemos;

antes, cuando los plazos sean cumplidos de nuestra frágil vida, un sólo espíritu, unidos los labios, de dos bocas se despida.

A mediados del siglo XIX Giosué Carducci incluyó en sus Iuvenilia (18561860) una traducción más que recreación del poema de Johannes Secundus con

sienta conmigo,/ porque el gozo de contigo,/ no me torne a dar la vida» (González Cuenca 2004, 472-473). Juan Meléndez Valdés tiene en cuenta esa primera estrofa de la canción, como ya he recordado en otro lugar (Morros, en prensa). 
el título significativo de "A Neera» porque conserva todos los elementos del original, desde la referencia a la yedra y el olmo iniciales hasta las preocupaciones que dejan de serlo ante la expectativa del abrazo y el beso de la amada (solo reproduzco la recreación de los primeros catorce versos en latín):

L'olmo e la verde sposa

vedi in florido amplesso accolti e stretti;

vedi a l'ilice annosa

attorcersi i corimbi giovenetti.

Deh! Se del roseo braccio

così, bianca Neera, m'avvincessi,

e tra ' 1 soave laccio

il capo stanco io nel tuo sen ponessi.

Un lungo amore insieme

giugnendo l'alme ognor, dolcezza mia

non altra gioia o speme,

non altro a desiar lo spirto avria.

Non me non me dal fiore

del caro labbro, fin di tutte brame

svegliar potria sopore,

non cura di Lieo, non dura fame.

Allor noi senza duolo

il fato colga; innamorati spirti

noi tragga un legno solo,

Pallido Dite, a' suoi secreti mirti (245-246).

En el siglo XX, los poetas de la generación aún llamada del 27 conocieron el libro al que pertenece el poema estudiado de Johannes Secundus. Pedro Salinas sin duda había leído los Basia del poeta holandés no solo por el interés que tuvo como profesor de literatura española por la recreación de Juan Meléndez Valdés, cuya poesía editó y prologó para La Lectura (1925), sino porque parece imitarlo en algunos de sus versos que forman la triología inspirada por la estudiante norteamericana Katherine R. Whitmore. Sin embargo, fue Federico García Lorca quien en noviembre de 1935 compuso un soneto que debe ponerse en relación directa con el poema de Johannes Secundus?

${ }^{7}$ Es difícil, pero no imposible, que Lorca hubiera leído la poesía de Johannes Secundus en su lengua original, pero en el caso de los Basia sin duda debió hacerlo en las recreaciones españolas y francesas de las que hemos hablado. Fuera de esa obra del holandés hay un poema suyo, titulado «Ad lectulum» (Elegiarum liber, II, 8), que hubiera podido inspirar su soneto inacabado que comienza « ¡Oh cama del hotel! ¡Oh dulce cama!». La elegía neolatina combina también el mismo sustantivo y adjetivo, pero no aplicados de la misma manera: «Lectule, qui domini lentum sine compare dulci/ pondus habes» (vv. 1-2). Aparte del soneto erótico del Siglo de Oro, «Oh dulce noche, Oh cama venturosa,/ testigo del deleite y gloria mía» (Foulché-Delbosc 1899, 335), cuyo anónimo autor debió conocer la elegía de Secundus, Lorca también tuvo en cuenta una de las odas de Juan Meléndez Valdés, que es 
El poeta granadino lo titula «soneto de guirnalda de rosas» para recrear el tópico ausoniano a partir de numerosas versiones, como podremos comprobar enseguida:

¡Esa guirnalda! ¡Pronto! ¡Que me muero! ¡Teje deprisa! ¡Canta! ¡Gime! ¡Canta!, que la sombra me enturbia la garganta, y otra vez viene y mil la luz de enero.

Entre lo que me quieres y te quiero, aire de estrellas y temblor de planta, espesura de anémonas levanta con oscuro gemir un año entero.

Goza el fresco paisaje de mi herida, quiebra juncos y arroyos delicados, bebe en muslo de miel sangre vertida.

Pero ipronto! Que unidos, enlazados, boca rota de amor y alma mordida, el tiempo nos encuentre destrozados.

Lorca empieza su soneto como Ronsard acaba sus «stanzes»: «Ah, je meurs! Ah, baise-moi!/ Ah, Maîtresse, approche-toi!»; ha mantenido el verbo «morir» y ha buscado otros dos verbos diferentes pero de un campo semántico similar: en su poesía «cantar» y «gemir» representan el éxtasis sexual, como lo pone de manifiesto en el romance de Amnón y Tamar en que el protagonista se masturba al pensar en el cuerpo desnudo de su hermana precisamente antes de recibir su visita:

En el musgo de los troncos

la cobra tendia canta.

Amnón gime por la tela

fresquísima de la cama (vv. 47-50; Morros 2018)

En Yerma, representada en Valencia el 5 de noviembre de 1935, coincidiendo con la composición de sus primeros Sonetos de amor oscuro, en el hotel Victoria de la ciudad, Lorca usa otra vez y también de manera consecutiva y con el mismo sentido sexual los dos verbos «cantar» y «gemir» (es el pasaje en que las lavanderas del pueblo, todas con hijos, ofrecen las claves, a través de imágenes de enorme erotismo, para tenerlos y ser fértiles):

\section{Lavandera $1 .^{\mathrm{a}}$}

Hay que juntar flor con flor cuando el verano seca la sangre al segador.

adaptación de otra elegía del holandés, la inmediatamente posterior a la de la cama y titulada «Ad Somnum»: «Oh noche deliciosa!/ ¡Oh afortunado lecho! ¡Oh gloria mía» (XIII, 1-3, Meléndez Valdés 1990, 173). 


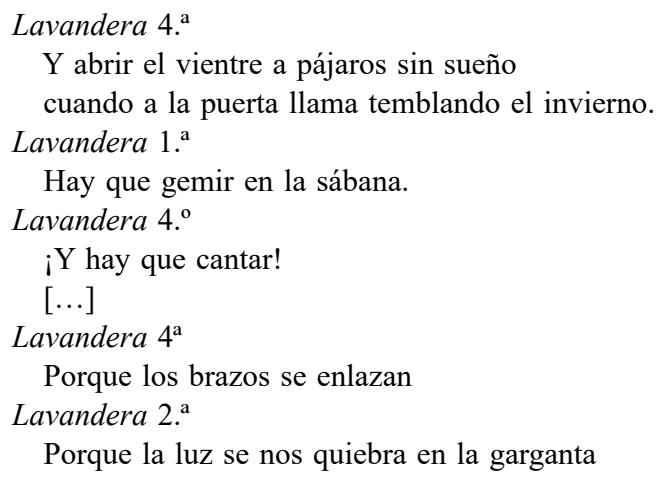

Es posible que para la exhortación de «tejer» con urgencia las rosas de la guirnalda que da título al soneto nuestro poeta se haya inspirado en el famosísimo romance de Góngora «Que se nos va la pascua, mozas» en que el poeta advierte a las muchachas de su barrio que aprovechen la juventud «porque de caducas flores/ teje el tiempo sus guirnaldas» (vv. 9-10). Lorca, en cualquier caso, da a «teje» el mismo sentido erótico que Ausonio había dado a «collige» al final de su elegía curiosamente titulada «De rosis» ${ }^{8}$. En los últimos versos del primer cuarteto nuestro poeta representa la muerte en términos parecidos, pero no idénticos, a Góngora en sus Soledades: si para el granadino es una «sombra» que «enturbia» su «garganta» con la luz fría de enero, para el cordobés es el agua fría que está a punto de beberse el peregrino en su naufragio (la «bebida muerte», II, 127, sin duda está inspirada en «entrábale la muerte con el agua», 2758, del Leandro de Boscán); pero en esos versos podría estar también describiendo una especie de mors osculi, reforzada por el numeral tan catuliano («otra vez vine y mil»), como en el soneto censurado de Ronsard, «mille et mille baizers donne moy je te prie» (v. 3), y también el éxtasis amoroso, como en Yerma, que deja sin aliento la garganta a la madre que pretende ser fecundada («la luz se nos quiebra en la garganta») ${ }^{9}$. En el hemistiquio «la luz de enero» puede haber una referencia a la expresión «la luna de enero», que forma parte de muchos refranes, como «Luna de ene-

${ }^{8}$ Pedrosa relaciona la «guirnalda de rosas» del soneto y de romance viejo «esa guirnalda de rosas» con un pasaje de La casa de Bernarda Alba en que Paca la Roseta aparece con «el pelo suelto y una corona de flores en la cabeza» como indicio de haber mantenido relaciones sexuales adúlteras con Maximiliano (2006, 203). El mismo Pedrosa 2013 (y antes Débax 1989) ha estudiado también la tradición hispánica, desde la Edad Media hasta el siglo XXI, del famosísimo verso de Ausonio. Deyermond 1977, Ferré 1983 y Costa Fontes 1984a y 1984b, a propósito de un pasaje de La Celestina, han analizado las connotaciones eróticas, en relación con las prácticas de la magia, de la actividad de 'hilar'.

${ }_{9}^{9}$ En Perlimplin, el protagonista describe el sentimiento de amor por su joven esposa Belisa «como un hondo corte de lanceta en mi garganta» (García Lorca 2010, 263); pensando en el suicidio final del marido, la imagen no deja de tener connotaciones también fúnebres. 
ro, amor primero» o «Luna de enero no tiene compañero», usados para subrayar la hermosura de la luna en ese mes del año porque a causa de la frialdad del invierno no se exhalan vapores de la tierra que impidan verla con claridad (por ese motivo es una luna con un poder hechizador solo comparable con la luna de agosto $)^{10}$. En esa mezcla de amor carnal y muerte, presente en cada uno de los versos del soneto, como estamos y seguiremos comprobando, la guirnalda de rosas también cobra un sentido fúnebre, en la línea del famoso poema de Christina Rosetti, «When I am dead», en el que pide a su amado que no plante rosas ni cipreses sobre su cabeza difunta, porque existía la costumbre de hacerlo: «Plant thou no roses at my head,/ nor shady cypress tree» (1970 vv. 3-4, 25). No conviene olvidar que en las versiones más antiguas de la muerte de Adonis, las lágrimas que derrama Venus sobre su cadáver se convierten en rosas rojas (véase notas 7 y 8).

En el segundo cuarteto Lorca recrea un contexto de amor mutuo, como en Johannes Secundus o el propio Lope, cuya obra dramática y poética conocía muy bien, pero posiblemente establece una diferencia entre «lo que me quieres y te quiero», reflejado quiásmaticamente en las imágenes del verso siguiente: «aire de estrellas» se corresponde con «[lo] que te quiero» al aludir con toda probabilidad al signo zodiacal del poeta, que es el de Géminis, signo presidido por el elemento aire (y quizá a la propiedad de la anémona, que suele arrancarla el viento); «temblor de planta» se relaciona con «lo que me quieres» y debe hacer referencia al amado, a imitación de las «stances» en que Ronsard llama a la amada «un faon qui tremble», inmediatamente después de esas invocaciones tan parecidas a las del comienzo de nuestro soneto. Ese segundo verso del segundo cuarteto puede interpretarse también en términos eróticos: «aire de estrellas» podría ser el del alma que procede del cielo y que vuelve a él a través de un beso (en uno de sus primeros poemas Lorca habla de los poderes curativos de la Virgen María con «su salivilla de estrellas», y si puede haber saliva hecha de estrellas también puede haber un aliento del mismo material); «temblor de planta» es el producido por su unión física con otro vegetal, como el que debe experimentar la yedra, aun sin alma, como en Lope, cuando se entrelaza al tronco de un árbol, y especialmente el miedo de la ninfa, en la oda de Meléndez Valdés, al notar el asimiento de la mano de su amante, como si fuera el tronco apresado por la yedra, tras recibir su beso: «¿De qué tiemblas en vano? [...]/ ya te tengo y te así con blanda mano» (XXI, 17-20).

La «espesura de anémonas» que entre los dos pretenden levantar con sus gemidos de un año entero puede referirse a los besos que necesitan darse, como

${ }^{10}$ El propio Lorca emplea esa expresión en la balada «Santiago», incluida en su Libro de poemas: «Era dulce el Apóstol divino,/ más aún que la luna de enero» (García Lorca 1996, 96). Para la explicación de esos refranes en relación con Lorca, véase Devoto 1973, 31-32, n. 5. 
en el poema de Johannes Secundus y en el soneto censurado de Ronsard, después de agotados por la relación sexual. En la tradición oriental, por su color rojo, las anémonas representan los labios de la amada y del amado, como deja claro Vicente Blasco Ibáñez en su traducción de Las mil y una noches, hecha sobre la francesa de Joseph Charles Mardrus (1898-1904) e impresa en la editorial valenciana Prometeo, hacia 1916, en un pasaje en que se plantea la superioridad de la belleza de los mozos sobre la de las mujeres: «Su boca es una manzanilla en flor, y sus labios dos anémonas húmedas» (vol. III, noche 392). Las anémonas también tienen connotaciones fúnebres, como la guirnalda de rosas, porque, en algunas versiones del mito, Adonis muere sobre un lecho de anémonas blancas que se vuelven rojas por su sangre tras ser destrozado por un jabalí ${ }^{11}$. En otras versiones Venus rocía con un néctar (o con sus propias lágrimas) el cuerpo agonizante del muchacho, de modo que cada gota de su sangre se transforma en la flor roja llamada anémona: el verbo «levantar» parece sugerido por esta versión, que es la de Ovidio, porque el néctar en contacto con la sangre produce una hinchazón «a la manera como suele levantarse en un cielo arrebolado una burbuja transparente» («ut fulvo perlucida caelo/ surgere bulla solet»), de la que nace una flor que debe su nombre al viento (Ovidio 1969, X: 731-735). En el soneto de Lorca este simbolismo de las anémonas puede tener un sentido cabal: el poeta se presenta a sí mismo en actitud agónica, como Adonis, desde el primer verso, y requiere el amor de su amante (como Venus buscaba también el último beso de Adonis) para que fructifique en una «espesura de anémonas» ${ }^{12}$. El verso «con oscuro gemir de un año entero» también parece adaptación (sobre todo por exigencias de la rima) de la hora entera que tarda la sangre del hijo de Mirra en transformarse en anémona: «nec plena longior hora/ facta mora est» (Ovidio 1969, vv. 734-735). Venus, volando en su carro alado, oye el gemido de su moribundo amante, pero cuando dejar caer el néctar sobre su sangre parece que el bello muchacho está ya sin vida: «agnovit longe gemitum morientis» (Ovidio 1969, v. 719).

En el primer terceto Lorca concreta ya la práctica amorosa que requiere de su amante usando fórmulas típicas en la tradición ausoniana del «collige virgo rosas». El verso inicial guarda relación sin duda con la muerte de Adonis: la

${ }^{11}$ Orringer (2006) estudió la versión de Bión, Lamento por Adonis, para ponerla en relación con el Llanto por Ignacio Sánchez Mejías, famoso torero atravesado por el asta de un toro. En esta versión Adonis sufre la herida no en la ingle sino en el muslo y las lágrimas que derrama Venus se transforman en rosas rojas (Bión 1796, 200).

${ }_{12}$ En otro pasaje de Las mil y una noches, Sherezade graba el siguiente epitafio en la tumba de Aziza: « ¿Una vez me detuve ante una tumba oculta en el follaje! ¡Siete anénomas lloraban sobre ella con la cabeza inclinada!»; y a la pregunta de a quién pertenece la tumba, la voz de la tierra contesta: « En esta paz duerme una enamorada!». Finalmente Schehrazada se compromete a cuidar la tumba de la difunta enamorada: "Yo plantaré aquí rosas y flores» (la traducción es también de Vicente Blasco Ibáñez, vol. II, noche 121). 
invitación a gozar «el fresco paisaje de mi herida» ha de entenderse como la sangre del amante de Venus convertida, al derramarse, en todo un paisaje de anémonas (es, por tanto, una invitación a gozar también de la muerte, simbolizada por las anémonas que han brotado de la sangre del poeta). Incluso el tercer verso del terceto es una versión bastante literal de ese mito pues Adonis sangraba por la ingle, la parte en la que el jabalí le clavó su colmillo entero: «trux aper insequitur totosque sub inguine dentes/ abdidit» (Ovidio, X, vv. 715-716). Sin embargo, dado su interés por los bucólicos griegos, Lorca pudo haber tenido en cuenta también la versión de Bión ${ }^{13}$ : para su «muslo de miel» pudo haber pensado en «herido el blanco muslo con el diente» (v. 10); y también para la urgencia de amor en el instante de la muerte pudo haber tenido en mente el beso que Venus habría querido dar a su amante aprovechando su último aliento:

Bésame en tanto que se siente
el besar delicioso de tus labios,
de tus purpúreos labios, mientras sale
del ánimo a mi boca, y a mi pecho
tu aliento con el último suspiro.
Así recogeré tu dulce encanto,
y beberé tu amor, y aqueste beso
guardaré como al mismo, al mismo Adonis ${ }^{14}$.

No cabe descartar que el detalle de la guirnalda, en un sentido erótico y fúnebre a la vez, lo haya adoptado también de Bión porque en su elegía Venus recuerda la costumbre de reclinar a Adonis en su colcha de oro entre guirnaldas cada vez que se acostaba con él; pero tras su muerte las flores de esas guirnaldas se han marchitado por completo: «en colcha de oro al tosco Adonis ama; reclínalo en guirnaldas y entre flores./ Todas con él, después de su fallecimiento,/ todas las flores mustian han quedado» (127).

Lorca toma la expresión «quebrar juncos» de la agricultura con el sentido de 'arrancarlos' de la vid para dejar crecer la cepa, y en su verso debe tener el mismo sentido erótico que arrancar una rosa o cualquier otra flor o planta: el arroyo o río es el lugar precisamente donde en la lírica popular la muchacha pierde su virginidad (la expresión usada en gallego portugués para expresar esa acción es «volver o rio» y en castellano 'volver el río', con un sentido análogo a «quebrar arroyos», con el sentido de enturbiar las aguas puras y cristalinas

${ }^{13}$ En su biblioteca tenía un ejemplar, comprado por su hermano, de Teócrito, idilios y epigramas, Tirteo, Odas anacreónticas, versión española de Germán Gómez de la Mata, hecha sobre la francesa de Leconte de Liste, publicada por la editorial valenciana de Prometeo (no consta el año). En este volumen no están traducidos ni los idilios de Bión ni los de Bosco. Véase Paepe y Fernández-Montesinos 2008, s. v. Teócrito.

${ }^{14}$ He usado la traducción de Joseph Antonio Conde, publicada en 1796, por ser respetuosa con el texto original; otras posteriores, contemporáneas a Lorca, como la de Ignacio Montes de Oca y Obregón (Bión 1914), no lo son y pecan de homofobia. 
en las que la moza llevaba a cabo el baño de amor con su amante) ${ }^{15}$. Entre sus Cantares galegos, compuestos casi todos entre 1934 y 1935 y editados en diciembre de 1935, en Santiago de Compostela, incluye la «Cántiga do neno da tenda» en que describe al niño Ramón de Sismundi, emigrado a Buenos aires, oyendo el sonido de una gaita que tocaba una «muñeira», danza típica de molineras; al acercarse a la ribera del estuario Río de Plata, para sentirse más cerca de la patria añorada, «Sauces e cabalos múos/ creban o vidrio das ágoas» (García Lorca 1996, 611). En este caso «crebar o vidrio das ágoas» no tiene el mismo sentido sexual que «quebrar [las aguas] arroyos», pero evoca merced a la música de la muñeira la actividad de la molienda en el agua de los ríos gallegos, con evidentes connotaciones eróticas. No cabe olvidar tampoco que «juncos» y «arroyos» pueden ser metáfora de 'muslos', como deja claro el propio Lorca en unos versos de su Perlimplín: «Entre mis muslos cerrados/ nada como un pez el sol./ Agua tibia entre los juncos» y «Plata de arroyos y espejos/ y anís de tus muslos blancos» (García Lorca 2010, 255 y 284).

En el último terceto Lorca emplea los mismos verbos que Johannes Secundus y Lope de Vega para representar la unión de la yedra con el olmo y/o la encina también con una clara connotación sexual. Es en esa postura en la que desea que los sorprenda el tiempo, sinónimo de la muerte: destrozados no implica solo la descomposición de los cuerpos por efecto del paso del tiempo sino también su agotamiento por haber practicado la relación sexual y haber alcanzado el éxtasis («destrozados» podría corresponderse de alguna manera con «languidus», «exanimis» y sobre todo «collabentes articulos» 'miembros destruidos, arruinados' del poema XIII de los Basia del holandés). Lorca no parece convencido, a diferencia de Johannes Secundus y Lope de Vega, de que esa manera de morir sea una garantía de que su amor perdure más allá de la muerte: la imagen de la destrucción de los cuerpos, tomado en un sentido literal, podría sugerir su desunión y desenlazamiento.

Pablo Neruda incluyó un soneto, el XCIII, entre sus mal llamados Cien sonetos de amor (Buenos Aires, 1959), en el que también trata el motivo estudiado hasta aquí de morir besándose con la persona amada y/o haciendo el amor con ella. Es un soneto que el poeta chileno dedica a su esposa Matilde Urrutia para pedirle que en el instante de su muerte abra la boca para morirse él también dándose un beso que dure una eternidad:

${ }^{15}$ El trovador gallego portugués que empleó la expresión fue Pero Meogo en varias de sus cantigas, pero la más famosa es «Levou-s'a a louçana, levou-s'a velida» en que la protagonista halla a su amigo, transformado en ciervo, en la fuente a la que ha ido a lavar sus cabellos: «Passa seu amigo, que lhi ben queria:/ o cervo do monte a áugua volvia» (Meogo 1966, 187 y Asensio 1957, 53). En la lírica castellana se emplea en la canción «Cervatica, que no me la vuelvas,/ que yo me la volveré», pero ya a la vez que en la versión castellana: «Cervatica, tan garrida,/ no enturbies el agua fría» (Blecua y Alonso 1956, 40); y también en el estribillo «Turbias van las aguas, madre,/ turbias van;/ mas ellas se aclararán» (ibíd., 108). 
Si alguna vez tu pecho se detiene, si algo deja de andar ardiendo por tus venas, si tu voz en tu boca se va sin ser palabra, si tus manos se olvidan de volar y se duermen,

Matilde, amor, deja tus labios entreabiertos porque este último beso debe durar conmigo, debe quedar inmóvil para siempre en tu boca para que así también me acompañe en mi muerte.

Me moriré besando tu boca loca fría, abrazando el racimo perdido de tu cuerpo, y buscando la luz de tus ojos cerrados.

$\mathrm{Y}$ así cuando la tierra reciba nuestro abrazo iremos confundidos en una sola muerte a vivir para siempre la eternidad de un beso (111).

Neruda conocía muy bien la poesía de Ronsard porque en sus memorias, Confieso que he vivido, llega a citar en cuatro ocasiones al poeta parisino, y en una de las cuatro se refiere a los dos tomos minúsculos de sus obras, «impresos en Francia en 1650», que le había enseñado Ilyá Ehrenburg cuando el escritor ruso lo visitó en Chile en 1954 (286). No he logrado localizar la edición mencionada por Neruda, y no parece referirse a la edición de sus Oeuvres, impresas entre 1629 y 1630 , en formato doceavo, porque las obras están repartidas en cinco volúmenes, no en dos: el soneto censurado debió aparecer en el último volumen entre las «autres pièces retranchées», y es entonces cuando debió de leerlo el chileno ${ }^{16}$. En cualquier caso, Neruda había recreado, bastantes años antes de ese encuentro con el poeta ruso, el soneto más conocido de Ronsard, perteneciente a los Sonnets pour Hélène, el XLIII de la segunda parte, el que comienza «Quand vous serez bien vieille, au soir à la chandelle», «Cuando estés vieja, niña (Ronsard te lo dijo)» (en Crepusculario, Santiago, 1923). En otra de las composiciones de ese su primer poemario, inspirándose en el soneto y las «stances» de los Amours de Cassandre, Neruda imaginó un mismo tipo de muerte con la «Morena, la besadora», que no es otra que la Virgen María, al recordar literalmente en ese final también el final del avemaría:

\footnotetext{
Bésame, por eso, ahora, bésame, Besadora, ahora y en la hora de nuestra muerte.
}

Amén.

\footnotetext{
${ }^{16}$ En su magnífico libro, Millares sitúa el soneto de Neruda en la tradición properciana y quevediana del amor post mortem $(2008,156)$, pero la tradición que sigue el poeta chileno es un poco distinta y cabe ponerla en relación con el poema de Johannes Secundus imitado por Ronsard.
} 
En su amago de soneto el chileno debió basarse en el soneto censurado del poeta francés al pretender viajar a través del beso y del abrazo hacia el más allá. Es posible que también hubiera leído la poesía de Juan Meléndez Valdés (y en concreto la oda XXI) en la edición de Pedro Salinas (Madrid, La Lectura, 1925): la idea de tener los labios unidos para que un solo espíritu salga de una misma boca en el momento de la muerte se la debieron sugerir más o menos directamente esos versos del poeta extremeño.

En las páginas anteriores hemos podido analizar el tratamiento que hace Johannes Secundus en dos poemas diferentes (Basia, II y XIII) del tema del beso, y a veces también de los abrazos, de los amantes en el instante de la muerte para emprender juntos el viaje hacia el más allá. El tema en un principio estaba relacionado al del tópico de la yedra adherida a los troncos de los árboles como símbolo de la unión física más que platónica de los amantes. Es posible que Gregorio Silvestre se inspirara en esos dos poemas para componer su famoso soneto «Habiéndose sido ya más combatida», y es seguro que lo hicieron, por caminos diferentes, Pierre Ronsard y Lope de Vega en sendos sonetos, pero el francés prescindió de la imagen de la yedra y el olmo, que sí conservó el madrileño. La diferencia estriba en que Silvestre no se plantea el beso entre los amantes como un acto que deba practicarse hasta el mismo momento de la muerte para poder descender juntos al Hades. En el siglo XVIII los poetas franceses y españoles (Claude Joseph Dorat y Juan Meléndez Valdés), al recrear, que no traducir, los Basia de Johannes Secundus, entendieron los besos y los abrazos como grados del amor que incluían también el último, el factum o coitus, de modo que pretendieron ser sorprendidos por la muerte mientras llegaban al éxtasis u orgasmo sexual. Es la tradición que tuvo en cuenta Federico García Lorca en su soneto de la guirnalda de rosas, perteneciente a la serie de Sonetos oscuros, en el que también representó en un segundo plano la muerte de Adonis, cuya sangre se transformó en anémonas rojas después de ser mortalmente herido por un jabalí en la ingle. Lorca dio a ese tema, en el que recordaba implícitamente el motivo de la yedra y el olmo, sobre todo en el último terceto, el tono del «collige virgo rosas» ausoniano, que ya le había dado Ronsard en su soneto censurado, pero interpretó el tema en su sentido exclusivamente sexual al emplear verbos, como «cantar» y «gemir», que en su obra tanto poética como dramática poseen esa connotación. Finalmente Pablo Neruda, influido especialmente por Ronsard y Meléndez Valdés, ofreció una versión más neoplatónica al reducirlo al beso final para hacerlo durar toda una eternidad.

\section{FUENTES}

Asclepiades de Samos (1604). En Florilegium, hoc est, veterum Graecorum Poetarum Epigrammata comprehensa libris septem, interprete Eilhardo Lubino. [Heildelberg]: In Bibliopolio Commeliano.

Belleau, Rémy. 1565. La bergerie. París: Gilles Gilles. 
Bión. 1796. Poesías de Anacreon, Teócrito, Bión y Mosco. Traducidas de griego por Joseph Antonio Conde. Madrid: Oficina de don Benito Caño.

Blasco Ibáñez, Vicente (s. f.). El libro de las mil y una noches. Traducción directa y literal del árabe por J. C. Mardrus, versión española... Valencia: Prometeo, 9 vols.

Boscán, Juan. 1999. Obra completa. Editado por Carlos Clavería. Madrid: Cátedra.

Carducci, Giosué (1871). Poesie. Florencia: G. Barbera.

Catulo (2009). Poesías. Editado por José Fernández Corte y Juan Antonio González Iglesias. Madrid: Cátedra.

Desportes, Philippe. 1592. Les oeuvres. Amberes: Arnould Coninx.

Dorat, Claude Joseph. 1770. Les baisers, précedes du Mois de mai, poème. La Haye: Delalain.

Escrivá, Comendador. 2004. «Canción». En Cancionero general de Hernando del Castillo, ed. Joaquín González Cuenca. Vol. II. Madrid: Castalia.

García Lorca, Federico. 1998. Yerma. Editado por Ildefonso-Manuel Gil. Madrid: Cátedra.

Góngora, Luis. 1994. Soledades. Editado por Robert Jammes. Madrid: Castalia.

Góngora, Luis. 2009. Antología poética. Editado por Antonio Carreira. Barcelona: Crítica.

Magny, Olivier. 1978. Les souspirs. Editado por David Wilkin. Ginebra-París: Droz.

Marullus, Michael. 2012. Poems. Editado por Charles Fantazzi. Massachusetts-Londres: Harvard University Press.

Neruda, Pablo. 1965. Cien sonetos de amor. Buenos Aires: Losada.

Neruda, Pablo. 1993. Confieso que he vivido. Barcelona: Seix Barral.

Ovidio. 1983. Metamorfosis. Traducido por Antonio Ruiz de Elvira, texto y notas de Bartolomé Segura Ramos. Vol II. Madrid: Consejo de Investigaciones Científicas.

Píndaro. 1993. Olímpiques. Editado por Manuel Balasch; introducción de Josep Maria Gómez Pallarés. Barcelona: Bernat Metge.

Pontano, Giovanni. 1973. Eclogae, ed. Liliana Monti Sabia. Nápoles: Liguori.

Ronsard, Pierre. 1622. "Huict sonnets de Ronsard non imprimez en ses oeuvres». En Le Parnasse des poetes satyriques o dernier recueil des vers picquants et gallards de nostre temps, 77-84. París.

Ronsard, Pierre. 1964. Les Amours. Editado por Françoise Joukovsky. París: Gallimard.

Rossetti, Christina Georgina. 1970. Selected Poems. Editado por Marya Zaturenska. Michigan: MacMillan.

Secundus Everaerts, Johannes. 1541. Opera nunc primum in lucem edita. Utrecht: Harmannus Borculous.

Secundus Everaerts, Johannes. 1979. Basia y otros poemas. Editado por Olga Gete Carpio. Barcelona: Bosch.

Silvestre, Gregorio. 1939. Poesías. Editado por Antonio Marín Ocete. Granada: Publicaciones de la Universidad.

Teócrito (s. f.). Idilios y epigramas, Tirteo, Odas anacreónticas. Traducción nueva del griego por Leconte de Lisle, versión española de Germán Gómez de la Mata. Valencia: Prometeo.

Tibulo. 1990. Elegías. Editado por Hugo Francisco Bauzá. Madrid: Consejo Superior de Investigaciones Científicas.

Vega, Lope de. 1983. Obras poéticas. Editado por José Manuel Blecua. Barcelona: Planeta.

Viau, Théophile de. 1622. Le Parnasse des poetes satyriques.

Virgilio. 1959. Énéide (Livres I-VI). Editado por Henri Goelzer y André Bellessort. Vol. I. París: Société d’Édition «Les Belles Lettres». 


\section{BIBLIOGRAFÍA CITADA}

Asensio, Eugenio. 1957. Poética y realidad en el Cancionero peninsular de la Edad Media. Madrid: Gredos.

Blecua, Alberto. 2006. «¿Signos viejos o signos nuevos? ('Fino amor’ y 'religio amoris' en Gregorio Silvestre)». En Estudios de historia literaria, 175-217. Barcelona: Crítica.

Blecua, José Manuel y Dámaso Alonso, eds. 1956. Antología de la poesía española. Poesía de tipo tradicional. Madrid: Gredos.

Bión. 1914. Poetas bucólicos griegos. Traducidos en verso castellano por Ignacio Montes de Oca y Obregón. Madrid: Sucesores de Hernando.

Costa Fontes, Manuel da. 1984. «Celestina's Hilado and Related Symbols». Celestinesca 8(2): 3-11.

Costa Fontes, Manuel da. 1984. «Celestina's Hilado and Related Symbols: A Supplement». Celestinesca 9(2): 33-38.

Débax, Michelle. 1989. «“Cogiendo rosas y lirios” ¿Erotismo codificado?». En Eros literario, coord. Covadonga López Alonso, 31-44. Madrid: Editorial Complutense.

Devoto, Daniel. 1973. «Notas sobre el elemento tradicional en la obra de Federico García Lorca». En Federico García Lorca, ed. Ildefonso-Manuel Gil, 23-72. Madrid: Taurus.

Deyermond, Alan. 1977. «Hilado-cordón-cadena: Symbolic Equivalence en La Celestina». Celestinesca 1(1): 6-12.

Egido, Aurora. 1982. "Variaciones sobre la vid y el olmo en la poesía de Quevedo: amor constante más allá de la muerte». En Homenaje a Quevedo, ed. Víctor García de la Concha, 213-232. Salamanca: Ediciones de la Universidad.

Ferré, Rosario. 1983. «Celestina en el tejido de cupiditas». Celestinesca 7(1): 3-16.

Foulché-Delbosc, Raymond. 1899. «136 sonnets anonymes». Revue Hispanique VI: 328-407.

García Lorca, Federico. 1996. Poesía. Editado por Miguel García-Posada. Barcelona: Galaxia Gutenberg - Círculo de lectores.

García Lorca, Federico. 2010. Amor de Don Perlimplín con Belisa en su jardín. Editado por Margarita Ucelay. Madrid: Cátedra.

Godefroy, Frédéric. 1888. Dictionnaire de l'ancienne langue française et de touts ses dialectes du IX au XV siècle. Vol. 8. París: F. Vieweg.

López Poza, Sagrario. 2005. «La difusión y recepción de la Antología Griega en el siglo de oro». En En torno al canon: aproximaciones y estrategias, ed. Begoña López Bueno, 15-62. Sevilla: Grupo PASO.

Meogo, Pero. 1966. O cancioneiro de Pero Meogo. Editado por X. L. Mendez Ferrin. Galaxia, Vigo: Galaxia

Meléndez Valdés, Juan. 1990. Poesía y prosa. Editado por Joaquín Marco. Barcelona: Planeta.

Millares, Selena. 2008. Neruda: el fuego y la fragua. Ensayo de literatura comparada. Salamanca: Ediciones Universidad.

Morros, Bienvenido. 2018. «Erotismo, cuerpo humano y fecundidad en El Romancero Gitano de Lorca». Hispanic Research Journal 19: 595-619.

Morros, Bienvenido. 2019. «Onanismo y/o masturbación entre Lorca y Dalí». En Paradigmas pervertidos, ed. Ricardo de la Fuente Ballestreros y Guadalupe Ramos Truchero, 63-100. Madrid: Visteria

Morros, Bienvenido. En prensa. «El comendador Escrivá y Angel González esperando la muerte». Boletín de la Real Academia Española.

Orringer, Nelson. 2006. «El diálogo con dos bucólicos griegos en el Llanto por Ignacio Sánchez Mejía». En La tradición clásica en la obra de Federico García Lorca, ed. José Mará Camacho Rojo, 199-207. Granada: Universidad. 
Paepe, Christian, y Manuel Fernández-Montesinos, eds. 2008. La biblioteca de Federico García Lorca. Catálogo general de los fondos documentales de la Fundación Federico García Lorca. Madrid: Fundación Federico García Lorca.

Pedraza, Felipe B. ed. 1993. Lope de Vega, Rimas. Cuenca: Universidad de Castilla-La Mancha.

Pedrosa, José Manuel. 2006. «La guirnalda de rosas: tradición y simbolismo en un romance español y sefardí». Miscelánea de Estudios Árabes y Hebraicos. Sección de Hebreo 55: 191-207.

Pedrosa, José Manuel. 2013. «Collige, virgo, rosas... y otras flores cortadas». Creneida 1: 179-213.

Rodríguez Alfageme, Ignacio. 2006. «Baco, Ciso y la hiedra. Apuntes para la historia de un tópico literario». En La tradición clásica en la obra de Federico García Lorca, 149-183. Granada: Universidad.

Fecha de recepción: 24 de diciembre de 2016.

Fecha de aceptación: 10 de marzo de 2017. 